\title{
An Assessment of the Ductile Fracture Behavior of Hot Isostatically Pressed and Forged 304L Stainless Steel
}

\begin{abstract}
A.J. COOPER, R.J. SMITH, and A.H. SHERRY
Type 300 austenitic stainless steel manufactured by hot isostatic pressing (HIP) has recently been shown to exhibit subtly different fracture behavior from that of equivalent graded forged steel, whereby the oxygen remaining in the component after HIP manifests itself in the austenite matrix as nonmetallic oxide inclusions. These inclusions facilitate fracture by acting as nucleation sites for the initiation, growth, and coalescence of microvoids in the plastically deforming austenite matrix. Here, we perform analyses based on the Rice-Tracey (RT) void growth model, supported by instrumented Charpy and $J$-integral fracture toughness testing at ambient temperature, to characterize the degree of void growth ahead of both a V-notch and crack in 304L stainless steel. We show that the hot isostatically pressed (HIP'd) 304L steel exhibits a lower critical void growth at the onset of fracture than that observed in forged 304L steel, which ultimately results in HIP'd steel exhibiting lower fracture toughness at initiation and impact toughness. Although the reduction in toughness of HIP'd steel is not detrimental to its use, due to the steel's sufficiently high toughness, the study does indicate that HIP'd and forged $304 \mathrm{~L}$ steel behave as subtly different materials at a microstructural level with respect to their fracture behavior.
\end{abstract}

DOI: $10.1007 / \mathrm{s} 11661-017-4005-1$

(C) The Author(s) 2017. This article is published with open access at Springerlink.com

\section{INTRODUCTION}

HoT isostatic pressing (HIP) is a component manufacturing technique that employs the use of high temperature and isostatically controlled pressure to consolidate metal alloy powder of desired chemistry into bulk metal under an inert (usually argon) atmosphere ${ }^{[1-3]}$ A good analogy to this is when a child forms a snowball with their hands. ${ }^{[4]}$ The most significant advantage of HIP over more conventional forging and casting lies within its ability to produce components with increasingly complex geometries, commonly referred to as near-net shape, since the consolidation of metal powder occurs within a prefabricated vessel, the shape of which governs the geometry of the HIP'd component. ${ }^{[5,6]}$ This increased design freedom allows the direct production of, for example, pipes with several T-piece junctions, nozzles, and elbows, without the need for additional machining or welding of subsequent components.

The potential to reduce welded joints from component manufacture is beneficial on several levels: the ability to avoid welding issues such as the risk of hot cracking, problems associated with having several

A.J. COOPER and R.J. SMITH are with the School of Materials, University of Manchester, Manchester M13 9PL, United Kingdom. Contact email: adam.cooper@manchester.ac.uk A.H. SHERRY is with the School of Materials, University of Manchester, and also with the National Nuclear Laboratory, Warrington WA3 6AE, United Kingdom.

Manuscript submitted August 24, 2016.

Article published online February 24, 2017 metallurgical zones (fusion line, heat-affected zone) in a single component, and weld residual stresses, which can provide the driving force for crack growth. Not having to perform the welding procedure in the first place also reduces the manufacturing time and, therefore, costs. In addition, the homogeneous and isotropic microstructure and smaller grain size produced by HIP lends itself better to nondestructive examination techniques, since the smaller grains interfere less with the ultrasonic inspection. ${ }^{[7]}$

In terms of mechanical properties, HIP typically produces material with a higher yield stress and ultimate tensile strength compared to equivalently graded forged material, which is generally attributed to the smaller grain size and isotropic nature of the HIP microstructure. ${ }^{[7]}$ However, the authors recently showed that HIP'd steels exhibit a slight reduction in impact toughness over a substantial temperature range. ${ }^{[8-10]}$ This has been attributed to the observation that HIP'd austenitic steel typically contains oxygen concentrations over an order of magnitude higher than those of "chemically equivalent" graded forged material. This significant increase in oxygen is thought to arise as a result of powder surface oxidation during one, or several, of the many HIP stages, beginning with gas atomization of the initial powder, during handling and storage of the metal powder, to filling of the canister. Despite the HIP procedure being performed under an inert atmosphere, the several stages prior to the actual HIP of the component currently make it extremely challenging to produce material that has less than $100 \mathrm{ppm}$ oxygen in the bulk as-HIP'd material. For reference, the forged 
steels we have tested previously contained between 15 and 25 ppm oxygen, ${ }^{[8,9]}$ typically an order of magnitude lower.

We have previously shown that this excess oxygen manifests itself as a fine array of nonmetallic oxide inclusions distributed homogeneously within the austenite matrix. ${ }^{[9]}$ Since ductile failure mechanisms operate via the initiation, growth, and coalescence of microvoids in a plastically deforming matrix, ${ }^{[1-13]}$ it follows that an increase in initiation site volume fraction within the matrix results in a greater number of nucleated voids and, more significantly, a reduced distance over which microvoids are able to grow under an applied triaxial stress before they coalescence with neighboring voids and fracture prevails. ${ }^{[14]}$ This results in lower impact toughness since the HIP'd material falls prey to an unzipping effect, whereby closely spaced voids, initiated at oxide inclusions, grow and coalesce as the crack propagates through the ligament ahead of the notch. More widely spaced voids are able to grow over larger distances before coalescence occurs with neighboring voids; therefore, the onset of coalescence is governed by void spatial distribution.

Numerical simulation of ductile failure in plastic voided materials typically focuses on the void growth process of the ductile failure mechanism, ${ }^{[15]}$ the more well-known constitutive micromechanics based models being proposed by Rice and Tracey, ${ }^{[16]}$ McClintock, ${ }^{[17]}$ Cockroft and Latham, ${ }^{[18]}$ and Gurson. ${ }^{[19]}$ The models generally share a similar foundation: the growth analysis of voids in a plastically deforming matrix under a remotely applied strain field, thus expressing the growth of a pore of radius $R$ as a function of incremental equivalent strain, ${ }^{[20]}$ with the models differing mainly in terms of the initial void size and geometry and their fundamental mathematical description of how the voids grow.

However, these models are often unable to completely describe the entire ductile fracture process accurately, and instead, fracture initiation (the point at which two neighboring voids meet and coalesce) is assumed to occur when a critical value of such a proposed void growth parameter is reached. ${ }^{[13]}$ This approach was first proposed by McClintock ${ }^{[17]}$ but has since been found to be an effective method when applied to other models.

Here we have employed the use of finite-element numerical models combined with the Rice-Tracey (RT) void growth model to simulate and characterize the critical conditions for ductile failure in the different materials in terms of the critical (maximum) void growth prior to fracture. This has been achieved by calculating RT parameters in close proximity to the tip of the Charpy $\mathrm{V}$-notch $\left(\mathrm{C}_{\mathrm{V}} \mathrm{N}\right)$ at crack initiation, as well as the evolution of the RT damage parameter and the complete loading history of the tests. All experimental Charpy data have been acquired in a previous study, ${ }^{[8]}$ and the Charpy impact energies and geometric dimensions of the failed Charpy specimens have been used herein.

In addition, we have performed experimental $J$-resistance $(J-\mathrm{R})$ fracture toughness testing of HIP and forged 304L, showing that previously reported results obtained from Charpy testing are also observed in more detailed fracture toughness testing performed at ambient temperature, and that the effects of oxygen are not only detrimental to a material's resistance to crack propagation, but also a materials fracture initiation toughness. We repeat the RT analysis of the critical conditions for crack initiation in HIP and forged compact tension $(\mathrm{C}(\mathrm{T}))$ fracture mechanics specimens.

\section{EXPERIMENTAL}

Mechanical testing was performed on HIP'd (HIP304L) and forged 304L (F304L) austenitic stainless steel. HIP'd 304L material was supplied by Areva and forged 304L stainless steel by Creusot Forge et Creusot Mécanique, Areva (Le Creusot, France). For HIP304L, stainless steel grade $304 \mathrm{~L}$ powder was heated from ambient temperature to $1123 \mathrm{~K}\left(1150{ }^{\circ} \mathrm{C}\right)$ at a rate of $633 \mathrm{~K}\left(360{ }^{\circ} \mathrm{C}\right) \mathrm{h}^{-1}$ and held at $1123 \mathrm{~K}\left(1150{ }^{\circ} \mathrm{C}\right)$ and $104 \mathrm{MPa}$ for a period of 180 minutes. Post-HIP heat treatment of HIP304L was performed by heating from room temperature to $1343 \mathrm{~K}\left(1070{ }^{\circ} \mathrm{C}\right)$ at $633 \mathrm{~K}(360$ $\left.{ }^{\circ} \mathrm{C}\right) \mathrm{h}^{-1}$, held for 280 minutes, and water quenched. Forged $304 \mathrm{~L}$ pipe was subjected to similar heat treatment as the HIP materials $\left(1343 \mathrm{~K}\left(1070{ }^{\circ} \mathrm{C}\right)\right.$, for $c a .250$ minutes) and water quenched.

The materials' elemental compositions (weight percent) and grain sizes are tabulated in Table I. Grain size measurements were conducted in accordance with ASTM E112-96. ${ }^{[21]}$

The $\mathrm{C}(\mathrm{T})$ specimens were machined in accordance with ASTM A370 recommended $^{[22]}$ dimensions $(60 \times$ $60 \times 25 \mathrm{~mm}$ ), and the notch was machined by electrical discharge machining (EDM). F304L C(T) specimens were extracted from a pipe section and machined with $\mathrm{CR}$ orientation, where $\mathrm{C}$ is the circumferential direction and $\mathrm{R}$ is the radial direction. HIP $\mathrm{C}(\mathrm{T})$ specimens were extracted from square blocks and machined with LT orientation, where $\mathrm{L}$ is the longitudinal direction and $\mathrm{T}$ is the transverse direction.

The round bar tensile test specimens were machined in accordance with ASTM E8/E8M recommended ${ }^{[23]}$ dimensions, with a gage length of $50 \mathrm{~mm}$, gage diameter of $8 \mathrm{~mm}$, and M10 thread. Tensile testing was conducted at a displacement rate of $0.5 \mathrm{~mm} \mathrm{~min}^{-1}$. The $\mathrm{C}(\mathrm{T})$ specimens were machined in accordance with ASTM A370 recommended ${ }^{[22]}$ dimensions $(60 \times 60 \times$ $25 \mathrm{~mm}$ ), and the notch was machined by EDM. F304L $\mathrm{C}(\mathrm{T})$ specimens were extracted from a pipe section and machined with CR orientation. HIP C(T) specimens were extracted from square blocks and machined with LT orientation.

Fatigue precracking of the $\mathrm{C}(\mathrm{T})$ specimens was performed using five precracking stages and a maximum stress intensity factor $K_{\max }$ of less than $20 \mathrm{MPa} \mathrm{m}^{-1 / 2}$ during the final crack growth to a final nominal $a / W$ of 0.55, in accordance with ASTM E1820. ${ }^{[24]}$ The CT specimens were then side grooved to 20 pct of the specimen thickness using a 90 deg angle. Fracture toughness data were obtained for both types of $304 \mathrm{~L}$ materials using the multispecimen $J$-R curve approach of ASTM E1820 (a total of five to seven specimens were 
Table I. Elemental Compositions of Tested Materials

\begin{tabular}{|c|c|c|c|c|c|c|c|c|c|c|}
\hline & & Grain Size & $\mathrm{Cr}$ & $\mathrm{Ni}$ & Mo & Mn & $\mathrm{Si}$ & $\mathrm{C}$ & $\mathrm{O}(\mathrm{ppm})$ & $\mathrm{N}$ (ppm) \\
\hline \multirow[t]{4}{*}{$304 \mathrm{~L}$} & specimen (wt pct) & - & 18.5 to 20.00 & 9.00 to 10.00 & - & $<2.00$ & $<1.00$ & $<0.035$ & 200 & - \\
\hline & forged & $94 \mu \mathrm{m}$ & 19.402 & 9.648 & 0.345 & 1.654 & 0.573 & 0.027 & 15 & 817 \\
\hline & powder (wt pct) & & 19.2 & 9.44 & - & 1.37 & 0.74 & 0.022 & 110 & - \\
\hline & HIP (wt pct) & $27 \mu \mathrm{m}$ & 19.5 & 9.45 & 0.01 & 1.33 & 0.72 & 0.022 & 120 & 840 \\
\hline
\end{tabular}

tested corresponding to each material). Each material $J$-R curve was characterized using a power-law regression curve fit through the valid data points, in accordance with the ASTM E1820, ${ }^{[24]}$ and forced through the point corresponding to maximum crack blunting, as described later. Fracture toughness testing was conducted in displacement control, with a load rate of $1 \mathrm{~mm}$ $\min ^{-1}$, until a sufficient clip gage opening was observed. Specimens were heat treated at $913 \mathrm{~K}\left(640{ }^{\circ} \mathrm{C}\right)$ for $c a .1$ hour following testing, in order to aid inspection of crack starting measurements, and opened by post-test fatigue, after which final crack lengths were measured using a nine-point average quantified by an optical microscope.

The C(T) specimens that exhibited the least amount of stable crack growth $(\Delta a)$ were prepared for metallurgical analysis by sectioning lengthways at the specimen midsection and perpendicular to the crack plane. Several Charpy specimens were also prepared in this fashion. All specimen sections were ground and polished in accordance with the recommended procedures in ASTM Practice E3-01 ${ }^{[25]}$ and lightly etched in $10 \mathrm{wt}$ pct oxalic acid. Electron microscopy was performed on the polished sections using an FEI Quanta 650 environmental scanning electron microscope (SEM) and an FEI Sirion SEM (FEI Company, Oregon), both equipped with field emission guns and electron backscattered diffraction detectors. Scanning electron microscopy was performed under vacuum using a $20 \mathrm{kV}$ accelerating voltage and a spot size of $4.0 \mathrm{~nm}$, at a working distance of $c a .10 \mathrm{~mm}$. Fractography was also undertaken on selected failed C(T) and Charpy specimens, using SEM and optical imaging.

The geometry of the blunted crack tip was measured using a Keyence VHX-5000 digital optical microscope (Osaka, Japan), which is able to build up a three-dimensional (3-D) map of the fracture surface through a series of two-dimensional (2-D) images. In order to compare the crack blunting geometry to crack-tip opening displacement (CTOD) values extracted from the numerical models, the $z$-height measurement of the blunted crack region was multiplied by two in order to account for both sides of the crack. A minimum and maximum threshold focus was set, through which the microscope recorded several images at specific increments, stitching together the individual 2-D images to produce a final 3-D image composed of all the in-focus snapshots. This process was repeated over a defined area of interest using a magnification 500 times. On the generated 3-D image, 15 profile lines were drawn, which spanned all stages of the fracture surface. An example of a generated height profile is shown in Figures 1(a) through (c).

\section{RESULTS}

\section{A. Microstructural Analyses}

Figure 2 shows micrographs of the sectioned $\mathrm{C}(\mathrm{T})$ and Charpy specimens viewed just below the fracture surfaces of both F304L and HIP304L materials. Ductile damage, in the form of voids, was observed ahead of the C(T) blunted crack tips in both HIP304L and F304L. The void population extended to varying distances ahead of the blunted crack tips. It was difficult to accurately quantify the characteristic distance over which void growth was observed ahead of the blunted tip in each material, but the extent of visible damage in the HIP material was found to be evident over a larger distance (200 to $300 \mu \mathrm{m}$ ) ahead of the blunted crack tip in comparison to that visible in the forged material $(<100 \mu \mathrm{m})$. In addition, concentrated ductile damage is visible close to the blunted crack tip and generally consists of fewer, larger voids in the forged specimen (Figure 2(a)), in contrast to the HIP specimen (Figure 2(b)), which exhibits a greater number of smaller voids.

The differences in void characteristics are more apparent in the Charpy specimens. F304L (Figure 2(c)) exhibits fewer, larger voids within 300 to $400 \mu \mathrm{m}$ ahead of the deformed notch profile and within close proximity to the fracture surface $(<150 \mu \mathrm{m})$, whereas HIP304L ((Figure 2(d)) exhibits a greater number of voids, which appear to be smaller in size. Both Charpy specimens exhibit elongated void growth in the direction of maximum plastic strain, which is characteristic of extensional void growth. In contrast, the $\mathrm{C}(\mathrm{T})$ specimens show comparatively spherical void growth more characteristic of "dilatational" growth, as a result of the high triaxial stress state at the crack tip.

\section{B. Ductile Void Growth Criterion Methodology}

Finite-element models of the $\mathrm{C}_{\mathrm{v}}$ and $\mathrm{C}(\mathrm{T})$ fracture toughness specimens were used to implement a theoretical void growth model for ductile materials given by Rice and Tracey. ${ }^{[16]}$ This approximate solution was derived in relation to growth (termed dilation, $D$ ) of a spherical void of radius $R$ in an infinite solid under a remotely applied radial strain rate and subjected to a range of different stress states:

$$
D=\frac{\dot{R}}{\dot{\varepsilon} R}=0.283 \cdot \exp \left(\frac{\sqrt{3} \sigma_{\mathrm{m}}}{2 \tau_{0}}\right)
$$

where $\dot{\varepsilon}$ is the remotely imposed strain rate, $\sigma_{\mathrm{m}}$ is the hydrostatic stress, and $\tau_{0}$ is the yield stress in shear. 
Expression [1] was previously simplified during an investigation by Beremin ${ }^{[26]}$ using the following equation:

$$
\ln \left(\frac{R}{R_{0}}\right)=0.283 \int_{0}^{\varepsilon_{\text {crit }}} \exp \left(\frac{3 \sigma_{\mathrm{m}}}{2 \sigma_{\mathrm{eq}}}\right) \mathrm{d} \varepsilon_{\mathrm{eq}}
$$

where $R_{0}$ is the initial radius of a nucleated void, $\sigma_{\mathrm{eq}}$ is the von Mises equivalent stress, and $\mathrm{d} \varepsilon_{\mathrm{eq}}$ is the increment of equivalent plastic strain.

The ratio of hydrostatic stress to von Mises equivalent stress defines stress triaxiality. The parameter $\ln \left(R / R_{0}\right)$ in expression [2] was used as a void growth rate parameter during this study. Herein this parameter will be referred to as the Rice-Tracey (RT) parameter to determine the predicted evolution of $R$ relative to $R_{0}$ using finite-element analysis. The Beremin group $^{[14]}$ compared void growth measurements obtained from metallographic samples with inclusion size measurements and numerical predictions, and the present work follows a similar methodology.

The RT model describes spherical growth of a single void and does not account for extensional void growth, the interactions between neighboring voids, nor does it predict ultimate failure. ${ }^{[27]}$

During this study, a postprocessing subroutine was developed to calculate $\ln \left(R / R_{0}\right)$ at each load increment of the analysis at integration points of FE models. Void growth characteristics associated with the Charpy specimen notch tip and fracture toughness specimen crack tip were evaluated using extrapolated nodal quantities of $\ln \left(R / R_{0}\right)$. Additionally, $\ln \left(R / R_{0}\right)$ was defined directly ahead of the notch and crack tips for each of the two stainless steel materials.

\section{Material Flow Properties}

Material properties for postyield behavior were defined by fitting the experimentally determined true stress $(\sigma)$ and true strain $(\varepsilon)$ data relevant to ambient temperature with a Ramberg-Osgood (RO) type hardening rule for each type of the SS304L steels studied. The RO expression is given by Reference 27

$$
\frac{\varepsilon}{\varepsilon_{0}}=\frac{\sigma}{\sigma_{0}}+\alpha\left(\frac{\sigma}{\sigma_{0}}\right)^{n}
$$

where $\varepsilon_{0}$ is the true strain corresponding to the limit of proportionality of the stress-strain curve, $\sigma_{0}$ is the true stress at the limit of proportionality, $\alpha$ is a constant derived from curve fitting, and $n$ is the strain-hardening exponent.

The material parameters used for ambient room temperature flow properties for forged $304 \mathrm{~L}$ and HIP 304L are tabulated in the graph in Figure 3. Fitting of the $\mathrm{RO}$ relationship was undertaken over $0.1<\varepsilon \leq 0.3$ for the HIP material, and $0.3<\varepsilon \leq 0.45$ filtered experimental data were used within the model prior to these strain ranges. The experimental test data and RO lines for the materials are shown in Figure 3. Linear elastic material properties of $E=208 \mathrm{GPa}$ and $v=0.3$ were used for both materials.
The strain rate sensitivity of the 304L stainless steel material was accounted for by fitting of the experimental tensile results for 304L stainless steel using a simple logarithmic expression fit to the data, which elevated the material stress parameter $\sigma_{0}$ in the RO expression with reference to the strain rate at material points in the model. ${ }^{[28-31]}$ Therefore, separate ratios of a dynamic material stress parameter, $\sigma_{0, d}$, to the quasi-static $\sigma_{0}$ value in expression [3] were defined corresponding to the range of strain rate to be encountered within the specimen (quasi-static to $3000 \mathrm{~s}^{-1}$ ). Expression [4] provides the derived formula defining the relationship between $\sigma_{0}$ and $\sigma_{0, d}$ with reference to the applied strain rate:

$$
\frac{\sigma_{0, d}}{\sigma_{0}}=0.0261 \ln (\dot{\varepsilon})+1.2127
$$

\section{D. $C_{V} N$ Impact Model}

A 3-D finite-element model of the $\mathrm{C}_{\mathrm{v}}$ specimen was built and used to describe the deformation and fracture initiation behavior of the material during testing. The model was a quarter symmetry detailed representation of the test specimen and loading arrangement, incorporating the anvil support and loading striker. The geometry of the model was defined in accordance with BS 10045. ${ }^{[32]}$ Eight-node full integration elements were used to represent the specimen geometry; layers of elements were defined through the specimen thickness and were biased in thickness toward the outer surface of the geometry. A refined mesh arrangement was used such that the aspect ratio of the elements surrounding the $\mathrm{V}$-notch tip was unity, with a minimum element size of $24 \mu \mathrm{m} \times 17 \mu \mathrm{m} \times 1 \mathrm{~mm}$. The equivalent cell size over which $\ln \left(R / R_{0}\right)$ was calculated was $c a .400 \mu \mathrm{m}^{2}$. The mesh arrangement for the specimen, striker, and anvil support with imposed boundary conditions for the complete Charpy test model is shown in Figure 4. The aspect ratio of the elements surrounding the notch tip was unity.

The FE analysis was undertaken using an implicit incremental analysis, which accommodated large strain gradient geometric effects within the ABAQUS 6.13 (Simulia, 2012, Dassault Systèmes, France) general purpose commercial software. Isotropic hardening and von Mises plasticity was adopted to describe the material yield and flow behavior. Material properties for postyield behavior were defined for each material using the $\mathrm{RO}$ fitted parameters described in the previous section and shown in Figure 3. Therefore, material models corresponding to F304L and HIP304L materials were implemented separately into two different models and were analyzed.

The loading was simulated by an imposed displacement of the loading striker to achieve deformation levels consistent with the measured test conditions. The anvil supports were fixed in position during the analysis. The anvil and striker were defined using linear elastic material properties typical of steel $(E=208 \mathrm{GPa}$, $v=0.3$ ). Contact constraints between the striker and 


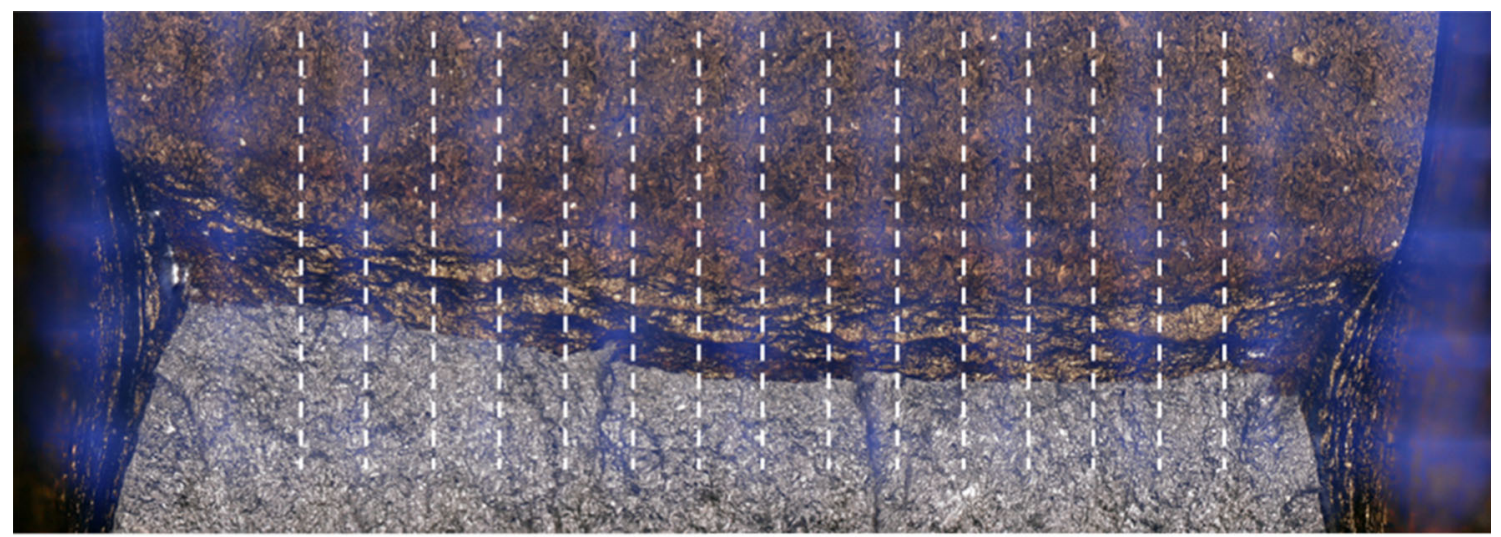

(a)

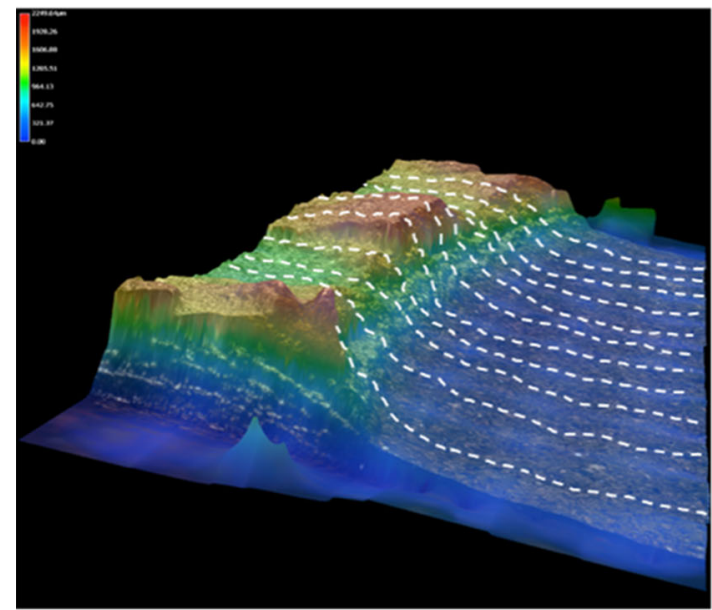

(b)

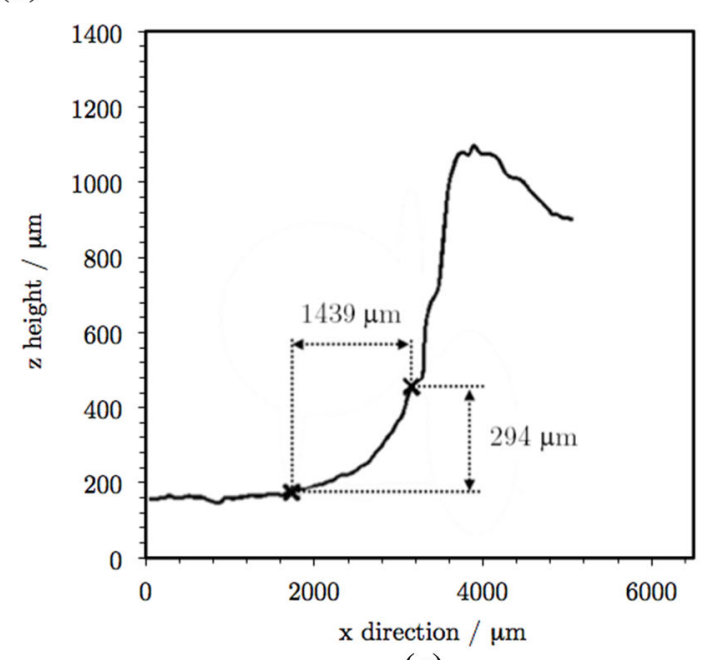

(c)

Fig. 1-Fracture surface of a failed C(T) specimen showing $(a)$ lines drawn from which height profiles were measured, $(b)$ a 3-D generated image of the fracture surface showing example profile lines, and $(c)$ a typical height profile from which the average $z$ height was calculated.

specimen, and anvil outer support and the specimen, were defined using a methodology that accounted for the friction properties of the materials. For the surface interaction properties to account for the contact between the specimen and the anvils/striker, a friction coefficient of 0.3 and slip tolerance of 0.005 were employed. A refined mesh was defined on the specimen contact surfaces to permit accurate description of the specimen deformation history at the anvil support location. The analysis was completed in $c a$. 150 loading increments for each set of material properties. The global reaction forces at the striker and the load line displacement values were obtained at each loading increment of each analysis. The $\mathrm{C}_{\mathrm{v}}$ finite-element models were validated with respect to the respective instrumented Charpy test data for the two materials of interest. Figure 5 shows the experimental load vs absorbed energy data measured during Charpy impact testing at an applied initial loading rate of $5.23 \mathrm{~ms}^{-1}$ in the two material types.

Approximate Charpy initiation energies, associated with the beginning of ductile tearing, were determined via measurement of the lateral contraction at the notch root of the V-notch on failed Charpy specimens (this dimension is shown in Figure 6). Since the exact point at which the notch root ends and ductile tearing begins was difficult to determine exactly, several contraction widths were measured surrounding the notch root/fracture transition for several specimens. As a result, the scatter in this measurement is significant and has been highlighted in Figure 7 using shaded bands (blue for HIP, red for forged). The contraction that occurs at this notch edge position during loading up to the point of fracture initiation was used, because it provided a reasonable displacement deemed to be representative of notch deformation at crack initiation and was reliably measurable. It is assumed that once fracture occurred, subsequent contraction at this point was limited as a result of crack propagation, with this point being left behind the propagating tip. Therefore, the increment in each $\mathrm{FE}$ analysis that predicted an equivalent amount of lateral contraction to that measured on the $\mathrm{C}_{\mathrm{v}}$ specimen was defined as the loading point corresponding to crack initiation for both F304L and HIP304L specimens, respectively. In reality, subsequent notch contraction is likely to occur as a result of extensive plastic deformation of the Charpy specimen; therefore, it is possible that the initiation energy values are slightly overestimated. Since each increment corresponds to a different amount of absorbed energy, it was possible to determine 
approximate initiation energies: $78 \mathrm{~J}$ for HIP and $93 \mathrm{~J}$ for forged 304L materials. These values of absorbed energy are labeled on the experimental force $v s$ absorbed energy plots (Figure 5). For HIP material, the initiation energy was ca. 22 pct of the total absorbed energy in the test. For forged material, this energy was $c a .23$ pct of the total absorbed energy.

The numerical models appear to be within good agreement with the experimental test data. For HIP material, agreement between the $\mathrm{FE}$ analysis and experimental data was within $c a$. 3 pct with respect to load. For the forged material, agreement was within $c a$. 1 pct. The HIP 304L model predicts slightly lower stresses than the experimental data, and we believe this is due to slight differences in the strain-rate sensitivity of the two materials. Since no strain-rate sensitivity behavior was available for HIP'd steel, we used that for forged 304L stainless steel.

Figure 7(a) shows how $\ln \left(R / R_{0}\right)$ evolves over the loading history for the two materials. The growth rate is comparable between HIP304L and F304L. The initiation energy of each material is labeled and indicates that, although the rate of void growth as a function of absorbed energy between the two materials is comparable, F304L exhibits a critical $\ln \left(R / R_{0}\right), \ln \left(R / R_{0}\right)_{\mathrm{c}}$, of 0.88 , whereas HIP $304 \mathrm{~L}$ exhibits $\ln \left(R / R_{0}\right)_{\mathrm{c}}=0.81$, a difference of nearly 10 pct. The value of $\ln \left(R / R_{0}\right)_{\mathrm{c}}$ is a measure of the maximum allowable void growth that can occur prior to microvoid coalescence and fracture, and it is this critical value of $\ln \left(R / R_{0}\right)$ that we have employed as an indicator for the beginning of fracture.

Figure 7(b) shows how $\ln \left(R / R_{0}\right)$ varies as a function of distance directly ahead of the notch tip, at each material's respective crack initiation energy. The distributions from the notch tip follow a similar profile, but HIP304L exhibits a consistently lower $\ln \left(R / R_{0}\right)_{\mathrm{c}}$ over a distance of $c a .2 \mathrm{~mm}$ from the notch root, suggesting that less void growth has occurred at initiation in HIP 304L compared to that in F304L.

\section{E. C(T) Model and J-R Fracture Toughness Test}

Similar FE analyses were performed using 3-D FE models of a $\mathrm{C}(\mathrm{T})$ fracture toughness specimen. Finite-element analysis of a $1 \mathrm{~T} \mathrm{C}(\mathrm{T})$ specimen during loading was conducted to study the ductile fracture initiation behavior exhibited by both the F304L and HIP304L stainless steel materials. The geometry of the 20 pct side-grooved C(T) specimen was compliant with ASTM E1820. ${ }^{[24]}$ A quarter model of the specimen geometry was defined and discretized using 20-node reduced integration elements by ABAQUS 6.13 (Simulia, 2013). Concentric rings of elements were used to define the crack-tip region, surrounding an initial blunted crack tip of $10 \mu \mathrm{m}$ radius. Variable thickness layers of elements biased toward the outer surface were defined through the specimen thickness, and a continuous mesh arrangement was employed along the crack front and side groove from the inner symmetry plane to the outside surface of the specimen geometry. The initial crack depth $\left(a_{0}\right)$ was defined to be the average depth of precrack in the experimental test specimens (nominal $a_{0} / W=0.55$ ). The material yield and flow properties corresponding to quasi-static loading conditions were identical to those adopted for the Charpy impact test modeling for both HIP304L and F304L. The test machine loading pin was modeled as integral to the test piece, as shown in Figure 8 (the boundary conditions and detail of the crack-tip mesh are also shown). A large strain analysis of the test was conducted and validated against experimental data up to the maximum loading level exceeding the fracture initiation according to the ASTM E1820 methodology. The analysis simulated the crack-tip blunting processes that preceded fracture initiation during testing. Crack-tip element size was $2.6 \mu \mathrm{m} \times 3.3 \mu \mathrm{m} \times 1 \mathrm{~mm}$. Contour $J$-integral values, $J$, were evaluated at each load increment along the crack front, and these were averaged using the crack-front element sizes to determine a single representative crackfront $J$ value, $J_{\text {ave }}$, at each increment of the analysis. The value of $J_{\text {ave }}$ was used as the loading measure for direct comparison with experimental results for specimens with small amounts of crack growth to determine the increment of the CT specimen analysis corresponding to initiation, as opposed to the ASTM E1820 definition of $J_{\text {IC }}(0.2 \mathrm{~mm}$ of ductile crack growth, $\Delta a)$. The numerical models were also validated against the experimental load vs load-line displacement data obtained from the individual fracture toughness tests, the results of which are presented in Figure 9.

The experimental $J$-R curves obtained for the two materials are presented in Figure 10. The $J$ initiation, $J_{i}$, toughness values were determined by measurement of the crack-tip blunting zone geometry of the failed $\mathrm{C}(\mathrm{T})$ specimens, as shown in Figure 1 (details are provided in Section II), which were then compared to computed CTOD values produced by the numerical models. The increment corresponding to the computed CTOD value was taken as the initiation increment, and the $J$-integral associated with this increment, calculated in accordance with ASTM E1820, ${ }^{[2]}$ was taken to be the fracture initiation toughness: the toughness of the material at the point of crack initiation, rather than that corresponding to a $0.2-\mathrm{mm}$ crack growth more commonly employed for the assessment of initiation toughness of austenitic stainless steels. This procedure was performed with respect to both materials. The corresponding crack extension associated with the initiation value of the $J$-integral was determined using a material-dependent blunting line with gradient $3.75 \sigma_{\mathrm{u}}{ }^{[33]}$ where $\sigma_{\mathrm{u}}$ is the ultimate tensile strength. HIP 304L exhibited ca. 30 pct lower initiation toughness than F304L: ca. $560 \mathrm{~kJ} \mathrm{~m} \mathrm{~m}^{-2}$ cf. $c a .800 \mathrm{~kJ} \mathrm{~m}^{-2}$. The power-law regression curves were then forced through these experimentally determined initiation $J$ values in order to improve the accuracy of $J_{i}$ estimation. For reference, more conventional $J_{0.2 \mathrm{BL}}$ values have also been determined for the two materials using the same material-dependent blunting lines, as previously noted, and are presented in Figure 10; however, we believe $J_{i}$ values to be more applicable to the results presented herein, since the employed numerical models do not simulate crack growth.

The different $J$-R curves indicate that not only does HIP304L exhibit a lower initiation toughness than 

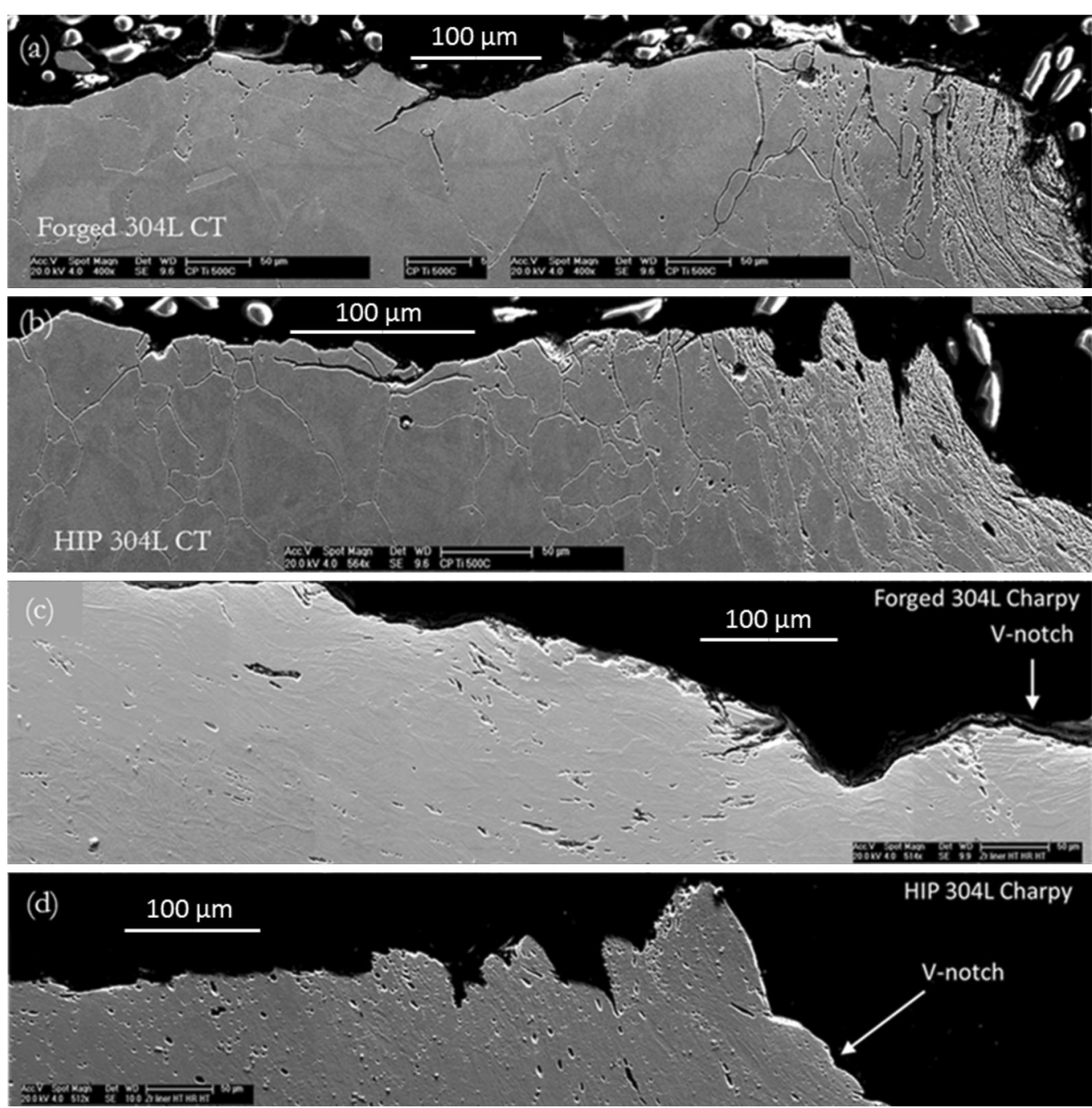

Fig. 2-Secondary electron images of (a) F304L C(T) microstructure, (b) HIP304L C(T) microstructure, (c) F304L Charpy microstructure, and (d) HIP304L Charpy microstructure, showing damage and ductile void growth beneath the fracture surface of the respective test specimens. In all of the figures, the notch/crack is on the right-hand side with the direction of crack growth from right to left.

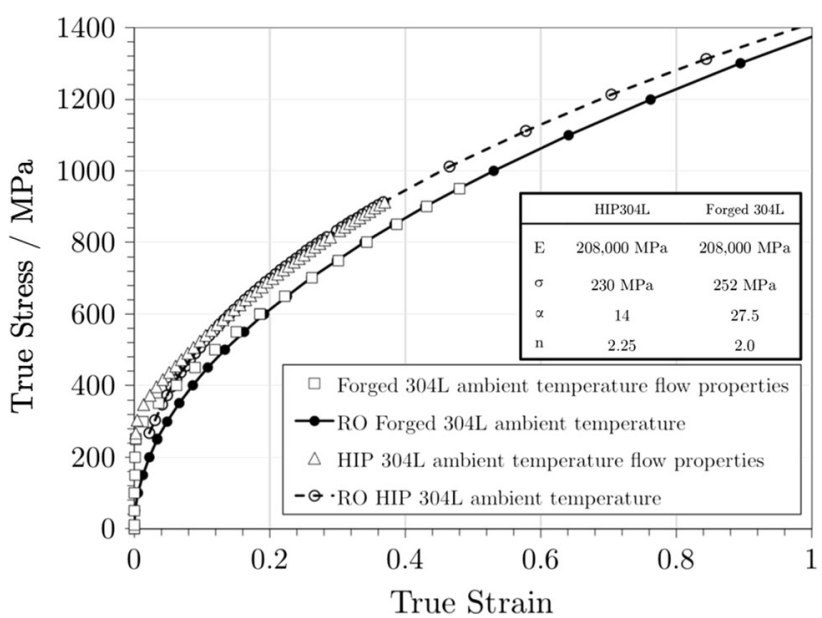

Fig. 3-Tensile test results at ambient temperature for forged and HIP'd 304L stainless steel materials with corresponding RO fits to the respective tensile test data.
F304L (this is true for both definitions $J_{i}$ and $J_{0.2 \mathrm{BL}}$ ), but that once the crack initiates, it experiences a lower resistance to crack propagation. Since we observe differences in both crack initiation and crack growth, this explains why the differences in $J_{0.2 \mathrm{BL}}$ values are greater than the difference between $J_{i}$ values, since $J_{0.2 \mathrm{BL}}$ incorporates the effects of both initiation toughness and $0.2 \mathrm{~mm}$ crack growth. The $J_{i}$ data have been used as a measure of crack initiation at which the corresponding values of $\ln \left(R / R_{0}\right)$ have been defined for each material.

Values of $\ln \left(R / R_{0}\right)_{\mathrm{c}}$ have been derived at the crack tip corresponding to the initiation toughness values, $J_{i}$, obtained from the material $J$-R curves. Figure 11(a) shows how $\ln \left(R / R_{0}\right)$ calculated at the crack tip evolves over the loading history of the $\mathrm{C}(\mathrm{T})$ test for the two materials, and the initiation $J$ values have been highlighted to indicate approximate values of $\ln \left(R / R_{0}\right)_{\mathrm{c}}$ at the crack tip at the point of initiation. Again, like that of the Charpy tests, it is of little surprise that $\ln \left(R / R_{0}\right)$ 


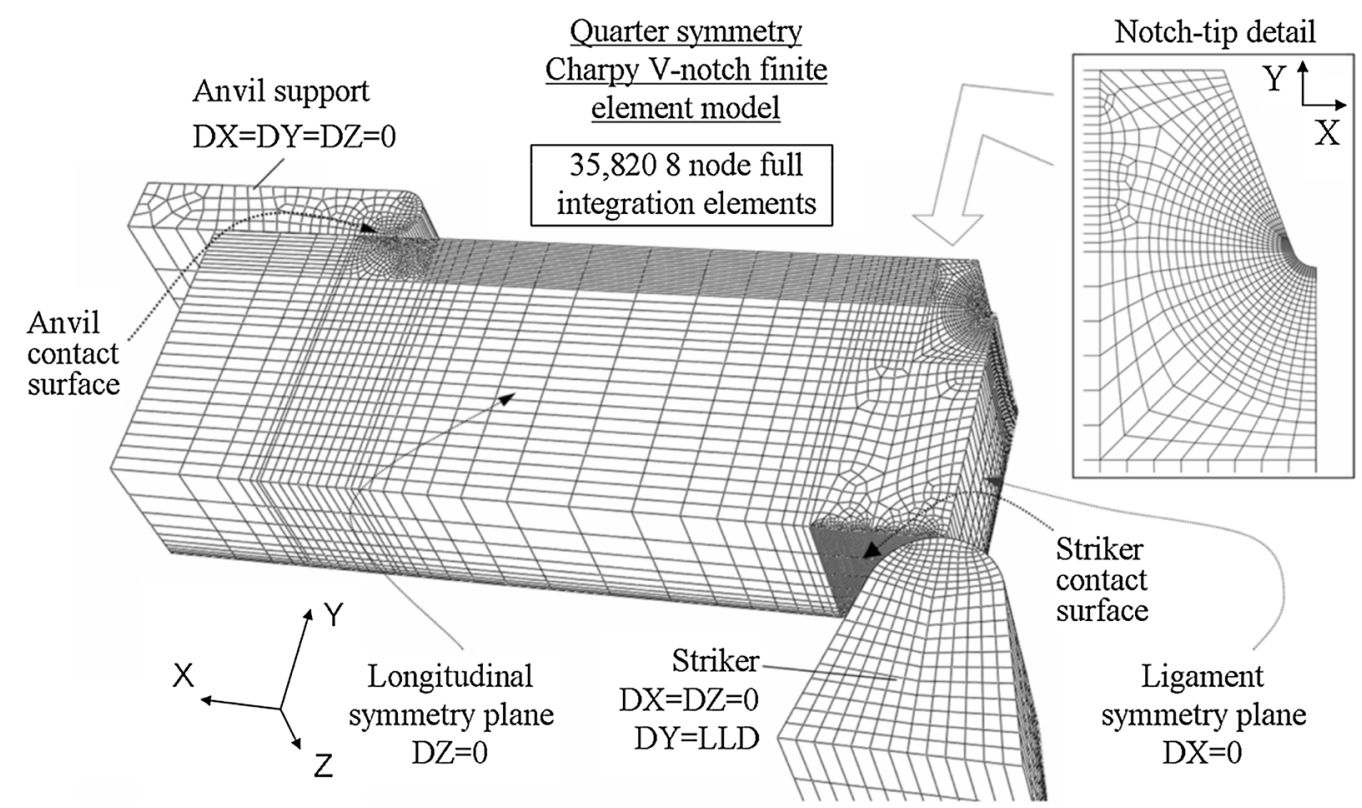

Fig. 4-Finite-element model details and mesh arrangement for the Charpy test specimen.

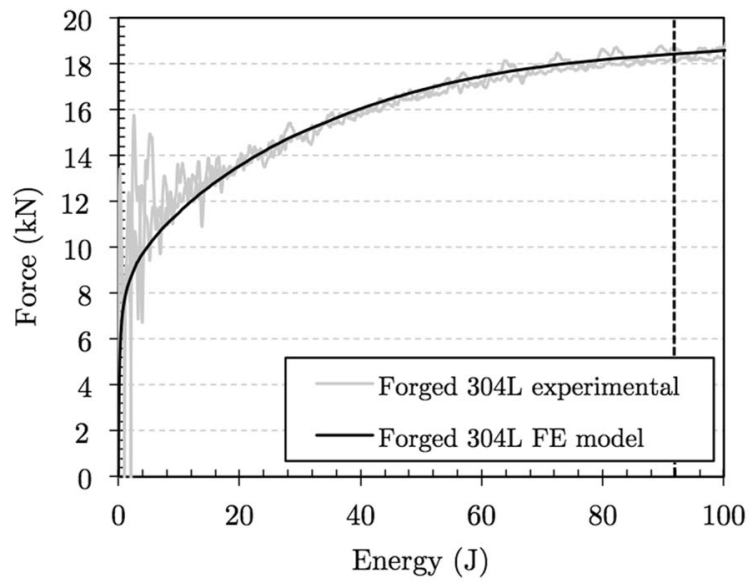

(a)

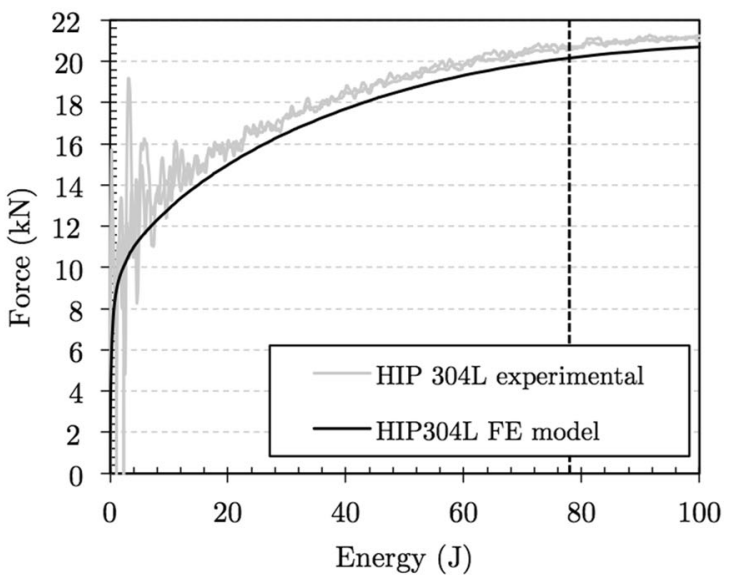

(b)

Fig. 5-Validation of finite-element models using instrumented Charpy test data for $(a)$ forged 304L and $(b)$ HIP 304L showing respective initiation energy values determined from lateral contraction measurements.

evolution for the two materials is comparable, given the similar load/displacement behavior from the experimental tests. However, because of the difference in initiation toughness values between the two materials, the $\ln (R /$ $R_{0}$ ) values corresponding to initiation are different: the critical $\ln \left(R / R_{0}\right)$ is $c a .3$ for $\mathrm{F} 304 \mathrm{~L}$ and $c a .2 .8$ for HIP304L. These values of $\ln \left(R / R_{0}\right)$ are in agreement with the literature values of $c a .3 .21^{[34]}$ for $25 \mathrm{~mm} \mathrm{C(T)}$ grade $12 \mathrm{NC} 6$ stainless steel specimens, where $\ln \left(R / R_{0}\right)$ was determined over a comparable cell size of $0.2 \mathrm{~mm}$. Figure 11(b) shows how $\ln \left(R / R_{0}\right)$ varies directly ahead of the crack tip up to a distance of $2 \mathrm{~mm}$, for both HIP304L and F304L, at their respective initiation levels. These data indicate that void growth is consistently greater in forged than in HIP'd material over a distance of $c a .2 \mathrm{~mm}$ from the crack tip.

\section{F. $C(T)$ and Charpy Comparisons}

Figure 12 compares the evolution of $\ln \left(\mathrm{R} / \mathrm{R}_{0}\right)$ over the loading history (absorbed energy) for $C(T)$ and Charpy models, reflecting HIP304L and F304L material properties. The values of $\ln \left(R / R_{0}\right)$ for the $\mathrm{C}(\mathrm{T})$ specimens have been plotted as a function of absorbed energy, rather than $J$, where energy in Joules was determined from the FE global force/displacement data. In addition, the $\ln \left(R / R_{0}\right)$ was recalculated for the $\mathrm{C}(\mathrm{T})$ model using an equivalent cell size of $c a .400 \mu \mathrm{m}^{2}$ so that $\ln \left(R / R_{0}\right)$ was calculated over the same areas for both the $\mathrm{C}(\mathrm{T})$ and Charpy models, and the $\ln \left(R / R_{0}\right)$ trends can be seen to decrease slightly when compared to the data in Figure11(a) as the analyses are performed over a slightly larger area. 

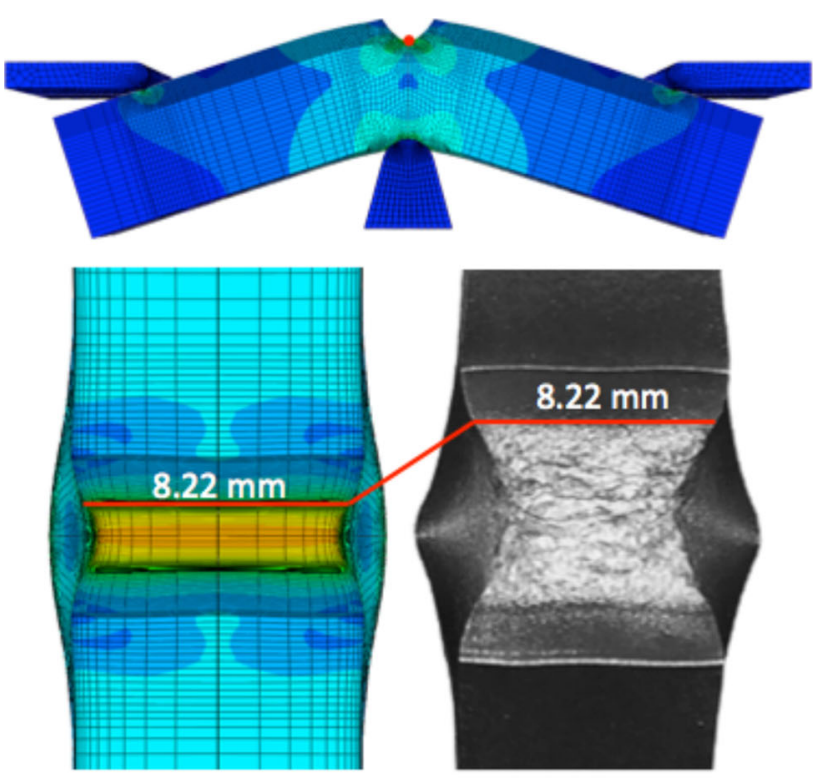

(a)


(b)

Fig. 6 - Comparisons between the finite-element model and the physical Charpy specimen after loading of $(a)$ forged 304L and $(b)$ HIP $304 \mathrm{~L}$, showing the lateral contraction measurement of the specimens.

It can be seen in Figure 12 that the Charpy initiation energies are higher than the $\mathrm{C}(\mathrm{T})$ initiation energies by between 20 and $40 \mathrm{~J}$. It is not clear why this increase in apparent initiation toughness arises; however, it could be attributed to the inertial effect, which stabilizes void growth and plastic flow and becomes dominant at strain rates in excess of $10^{3} \mathrm{~s}^{-1} \cdot{ }^{[35,36]}$ As detailed earlier, it is possible that the Charpy initiation energies are slightly overestimated due to the possibility of subsequent notch contraction during ductile tearing as a result of extensive plasticity throughout the Charpy specimen. It is thought that the high strain rate of the Charpy test $\left(c a .5000 \mathrm{~s}^{-1}\right.$ at the notch root), and therefore the reduced void growth rate associated with the inertial effect in the Charpy test, coupled with the lower degree of triaxiality ahead of the V-notch, should yield smaller void growth when using RT model predictions; therefore, the lower evolution trends in Figure 12 are considered sensible.
For these reasons, it could be rationalized that any damage model employed to predict void growth in Charpy specimens should predict smaller void growth than $\mathrm{C}(\mathrm{T})$ specimens.

In order to make meaningful comparisons between the Charpy and $\mathrm{C}(\mathrm{T})$ models at fracture initiation, the average value of $\ln \left(R / R_{0}\right), \ln \left(R / R_{0}\right)_{\text {ave }}$, has been determined over equivalent microstructural areas for the geometries at their respective initiation increments. Definition of the microstructural areas was conducted using a concentric arrangement of rings of elements emanating from the notch and crack-tip regions of the models. This was achieved by determining the dimensions of a segment of material directly ahead of the notch/crack tip, which was equivalent in area between the two models, denoted by $A_{\text {total }}$. The segment of material was composed of the notch symmetry line; an outer radial line, which was defined using an included angle of $\theta=45 \mathrm{deg}$; and an outer circumferential line corresponding to the outer radius $r_{0}$, as shown schematically in Figure 13. Within each segmented region (corresponding to a single $r_{0}$ value) of the finite-element models, the values of $\ln \left(R / R_{0}\right)$ were averaged by weighting the area of each finite element relative to the total area of the deformed region (on the specimen longitudinal symmetry plane), and termed $\ln \left(R / R_{0}\right)_{\text {ave }}$. Concerning the $\mathrm{CT}$ specimen, $\ln \left(R / R_{0}\right)$ averaging was undertaken at a loading level corresponding to ductile fracture initiation: an applied $J$-integral equal to $J_{\mathrm{IC}}$, as described earlier. A parametric study of the values of $\ln \left(R / R_{0}\right)_{\text {ave }}$ concerning the CT fracture toughness specimens of the microstructurally dissimilar forged and HIP stainless steel 304L material was undertaken to determine the average value of $\ln \left(R / R_{0}\right)$ over equivalent microstructural areas, as shown in Figure 14.

From Figure 14, the $\ln \left(R / \mathrm{R}_{0}\right)_{\text {ave }}$ values follow the same patterns as shown earlier: F304L consistently exhibits a slightly larger void growth than HIP304L at the point of crack initiation. The $\ln \left(R / R_{0}\right)_{\text {ave }}$ for the CT model is significantly larger at the crack tip but falls away rapidly as the area surrounding the crack tip increases. In contrast, $\ln \left(R / R_{0}\right)_{\text {ave }}$ for the Charpy model is much lower at the notch tip and decays much more gradually. Both models' $\ln \left(R / R_{0}\right)_{\text {ave }}$ converge to $c a .0 .2$ as area increases. The data help to explain the nature of the two competing phenomena controlling fracture behavior: critical $\ln \left(R / R_{0}\right)$ and microstructurally significant area. From Figure 14, it can be seen that if materials have equivalently sized microstructurally significant areas, then they must have different values of critical $\ln \left(R / R_{0}\right)$. Conversely, for the two materials to have the same values of critical $\ln \left(R / R_{0}\right)$, they must have different microstructurally significant areas/lengths. The microstructural work previously in References 8 and 10 indicates that the two materials have different microstructurally significant distances, in terms of the distance between particles, which act as initiation sites for ductile void nucleation. However, the difference in fracture surface characteristics ${ }^{[10]}$ (ductile coalescence radii), together with the different initiation toughness values corresponding to different $\ln \left(R / R_{0}\right)$ values, indicates that the two materials also have significantly 


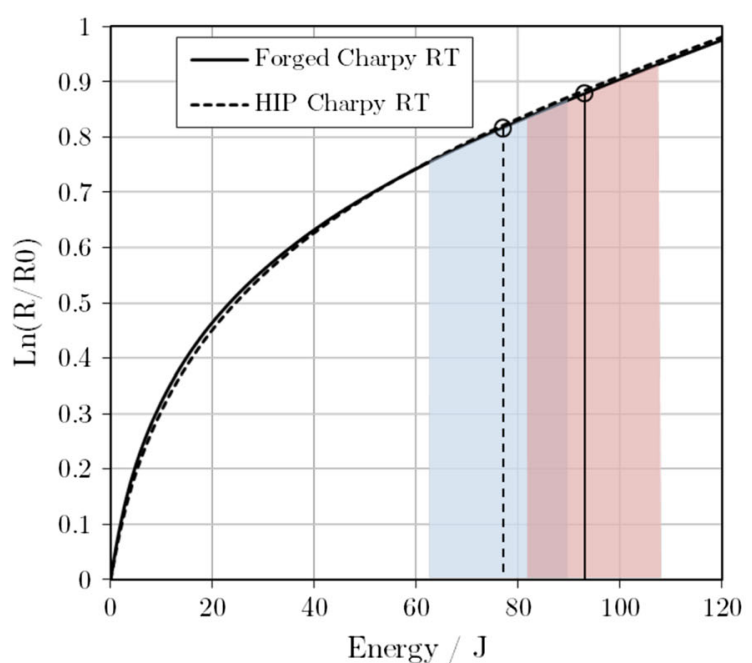

(a)

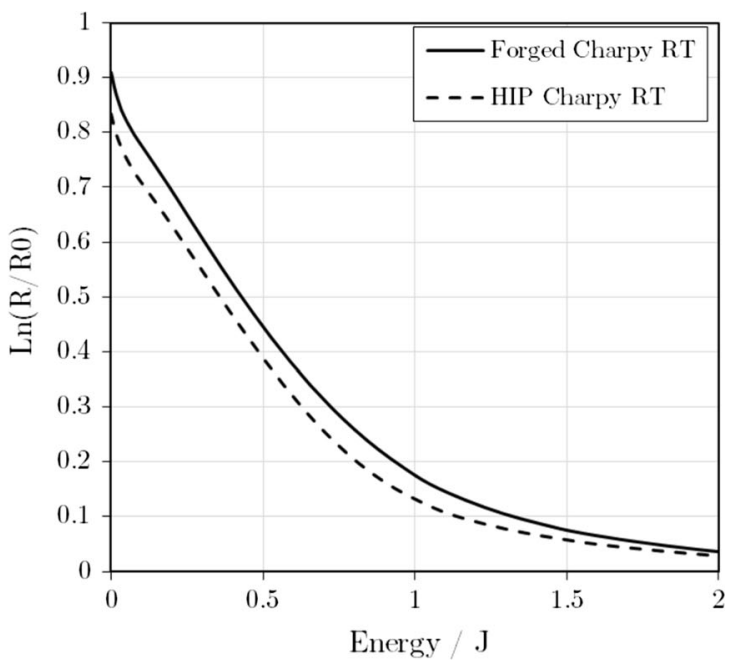

(b)

Fig. $7-(a) \operatorname{Ln}\left(R / R_{0}\right)$ evolution at crack tip with loading for HIP 304L and forged 304L showing their respective initiation energies; (b) distribution of RT ahead of the Charpy notch tip for HIP304L and F304L at their respective initiation energies.

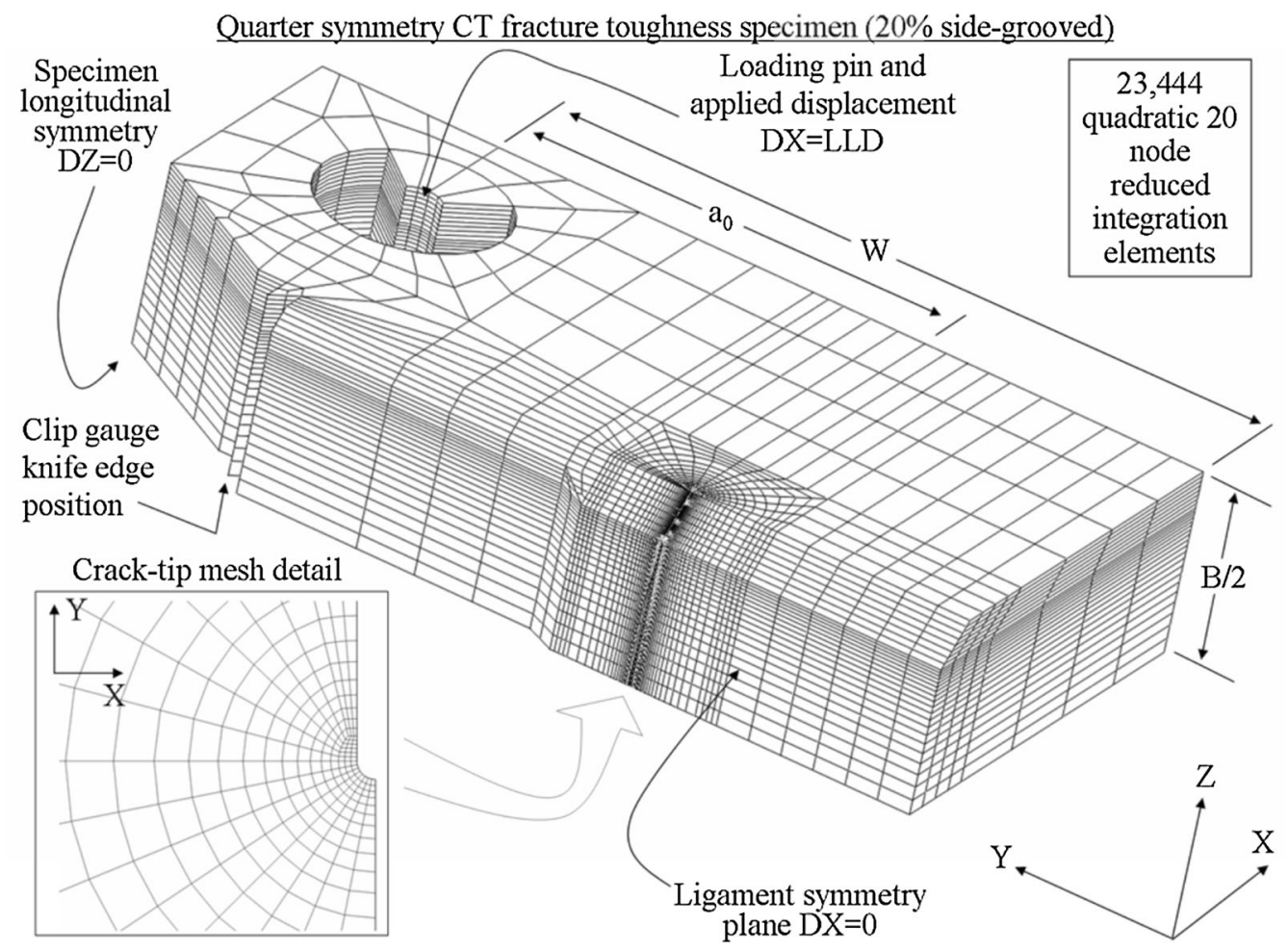

Fig. 8-Finite-element model details and mesh arrangement for the $\mathrm{C}(\mathrm{T})$ test specimen.

different critical $\ln \left(R / R_{0}\right)$ values. In effect, it is likely that the two materials actually have both different critical $\ln \left(R / R_{0}\right)$ values and microstructurally significant areas, since a larger microstructural area results in larger distances over which voids can grow and therefore, by definition, a larger critical $\ln \left(R / R_{0}\right)$. Consequently, HIP and forged variants of Type 304L, despite having not too dissimilar grain size and chemistry, behave as fundamentally different materials during fracture. The higher oxygen content of the HIP steel results in a greater number of oxide particles in the microstructure, which results in a significantly smaller microstructurally significant area and also exhibits a smaller critical value of $\ln \left(R / R_{0}\right)$ at which fracture initiates.

Finally, Figure 15 shows the FE contour maps for equivalent plastic strain, von Mises stress, and $\ln \left(R / R_{0}\right)$ for the $\mathrm{C}(\mathrm{T})$ specimen and Charpy specimen for the forged 304L at initiation. Contours are shown to extend over a larger distance from the notch root for Charpy than they do for $\mathrm{C}(\mathrm{T})$, reflecting the localized plasticity 


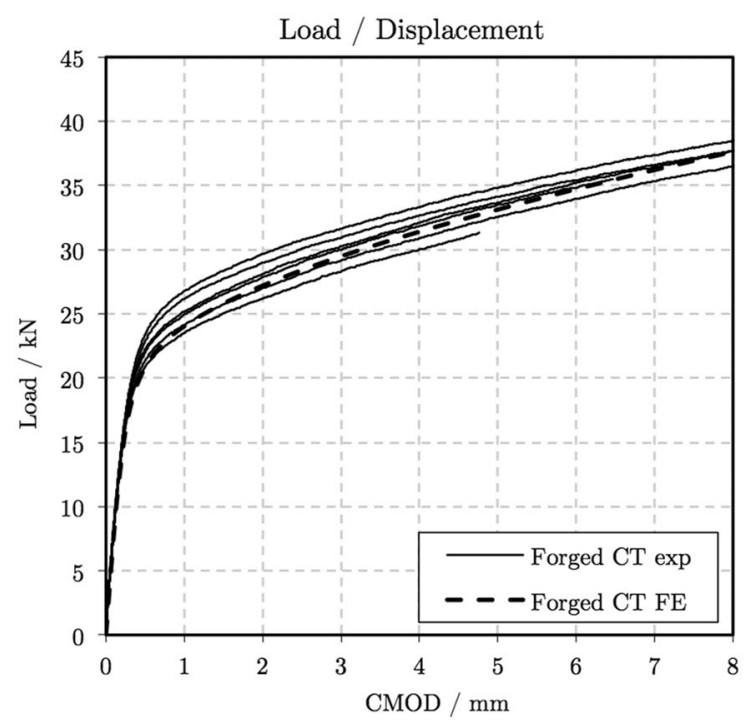

(a)

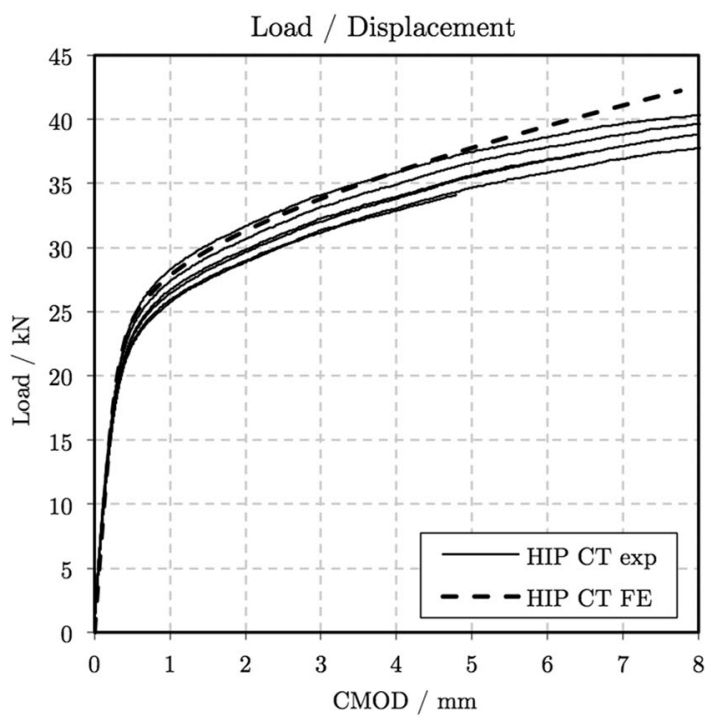

(b)

Fig. 9-Experimental (solid lines) and numerical (dashed lines) load and displacement fracture toughness test results for $(a)$ F304L and (b) HIP304L stainless steel materials.

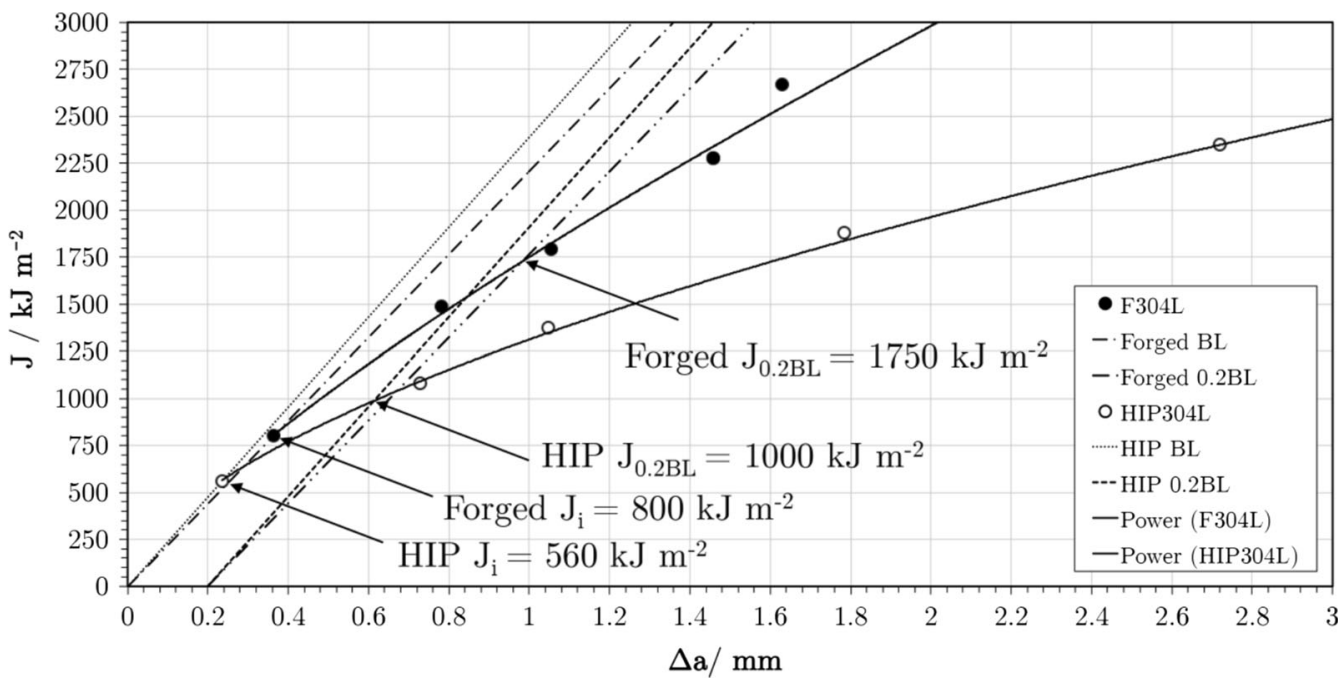

Fig. 10-Fracture toughness $J$-R curve for HIP (white data) and forged (black data) 304L stainless steel.

imposed by the high constraint geometry of the $\mathrm{C}(\mathrm{T})$ specimen. Because the $\mathrm{C}(\mathrm{T})$ specimen's plastic zone is more local to the crack tip, and the stresses and strains within the plastic zone are higher than those observed in the Charpy specimen, this can help us visualize why predicted $\ln \left(R / R_{0}\right)_{\text {ave }}$ values are significantly higher in the $\mathrm{C}(\mathrm{T})$ specimen close to the crack tip and also why the $\ln \left(R / R_{0}\right)_{\text {ave }}$ decreases much more rapidly with increasing area than observed for the Charpy models, where $\ln \left(R / R_{0}\right)_{\text {ave }}$ decays much more steadily.

\section{DISCUSSION}

We have shown that HIP304L and F304L exhibit similar void growth rate characteristics, shown by their similar respective $\ln \left(R / R_{0}\right)$ evolution over loading history data (Figure 12). This was the case for both Charpy and C(T) models and is a sensible result given the similar stress/strain behavior of the two materials. However, appreciable differences in void growth behavior are observed between HIP304L and F340L when considering the critical $\ln \left(R / R_{0}\right)$ value required to cause microvoid coalescence, i.e., fracture initiation. The magnitude of the critical $\ln \left(R / R_{0}\right)$ is governed by a material's fracture initiation toughness, or an elastic-plastic material's fracture initiation toughness is governed by the magnitude of its critical $\ln \left(R / R_{0}\right)$. By physical examination of the fractured specimens (measuring the extent of blunting zone for $\mathrm{C}(\mathrm{T})$ and lateral contraction for Charpy), significantly different initiation increments, and therefore critical $\ln \left(R / R_{0}\right)$, were obtained for HIP304L and F304L, with the F304L model yielding significantly larger void growth ratio 


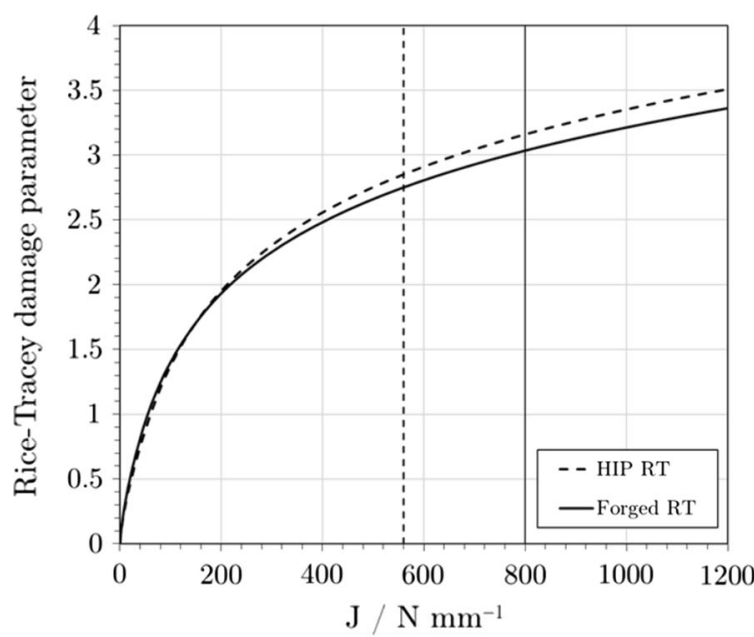

(a)



(b)

Fig. 11- (a) Evolution of $\ln \left(R / R_{0}\right)$ at the crack tip with loading and $(b)$ distribution of $\ln \left(R / R_{0}\right)$ ahead of the crack tip at the initiation increment, for the $\mathrm{C}(\mathrm{T})$ specimens.



Fig. 12-Comparison of $\ln \left(R / R_{0}\right)$ at the crack/notch tip as a function of absorbed energy for F304L and HIP304L calculated from Charpy and $\mathrm{C}(\mathrm{T})$ models.

values than the HIP304L model at the point of fracture initiation. Since the maximum allowable void growth is proportional to the intervoid spacing in a material's microstructure, and since a higher density of void nucleation is possible in the HIP matrix due to the greater number of initiation sites, it follows that voids in forged $304 \mathrm{~L}$, in theory, should be permitted to undergo growth over greater distances before falling prey to microvoid coalescence and fracture.

The initiation energy values obtained for the Charpy models were obtained by comparison of the finite-element models to lateral contraction measurements of the Charpy specimens at the notch root. The notch root was selected since it was deemed representative of the notch tip loading conditions and was easily measurable using a high-resolution 3-D optical microscope. Since crack growth occurs from the notch root, it was assumed that once crack initiation occurs, the notch root is effectively unloaded and any subsequent plastic deformation occurs ahead of the notch root. However, this is not strictly the case since the entire Charpy specimen continues to deform plastically while simultaneously undergoing crack growth, and it should be assumed that the notch root undergoes at least a small amount of further lateral contraction as the test proceeds. Therefore, the initiation energies should be deemed a slight overestimation, because of the continuing lateral contraction of the notch root with loading, and should be treated with caution. Nonetheless, this methodology serves to acquire approximate values of crack initiation in a Charpy test without the need to perform numerous interrupted Charpy impact tests.

The greater void growth predicted by the RT calculations for F304L is in agreement with the sectioned fractured specimens shown in Figure 2, where voids appear to have slightly larger radii than voids present close to the crack tip/notch root in the HIP304L. Furthermore, the sectioned specimens in Figure 2 generally exhibit fewer, larger voids in F304L than HIP304L, which is also in agreement with the microstructural and fractographic data reported previously in References 8 and 10, which show both fewer inclusions in the microstructure of F304L and larger ductile dimples on the F304L fracture surface. In addition, the $\ln \left(R / R_{0}\right)$ predictions are in agreement with the significantly different void radii of the ductile dimples on the fracture surfaces in Reference 10, whereby F304L exhibits both larger ductile dimpling on the fracture surface and a larger $\ln \left(R / R_{0}\right)_{\mathrm{c}}$.

As well as calculating $\ln \left(R / R_{0}\right)$ at the crack tip/notch root over the loading history of the models (Figures 7(a) and 11(a)), we have studied how $\ln \left(R / R_{0}\right)$ varies as a function of distance ahead of the crack tip/notch root at each respective crack initiation $J$-integral for a C(T) specimen and absorbed energy for a Charpy specimen. The $\mathrm{C}(\mathrm{T})$ model consistently yields much larger values of $\ln \left(R / R_{0}\right)$ than the Charpy model. Although the exact reason for this currently has not been established, it is believed to be due to several fundamental differences 


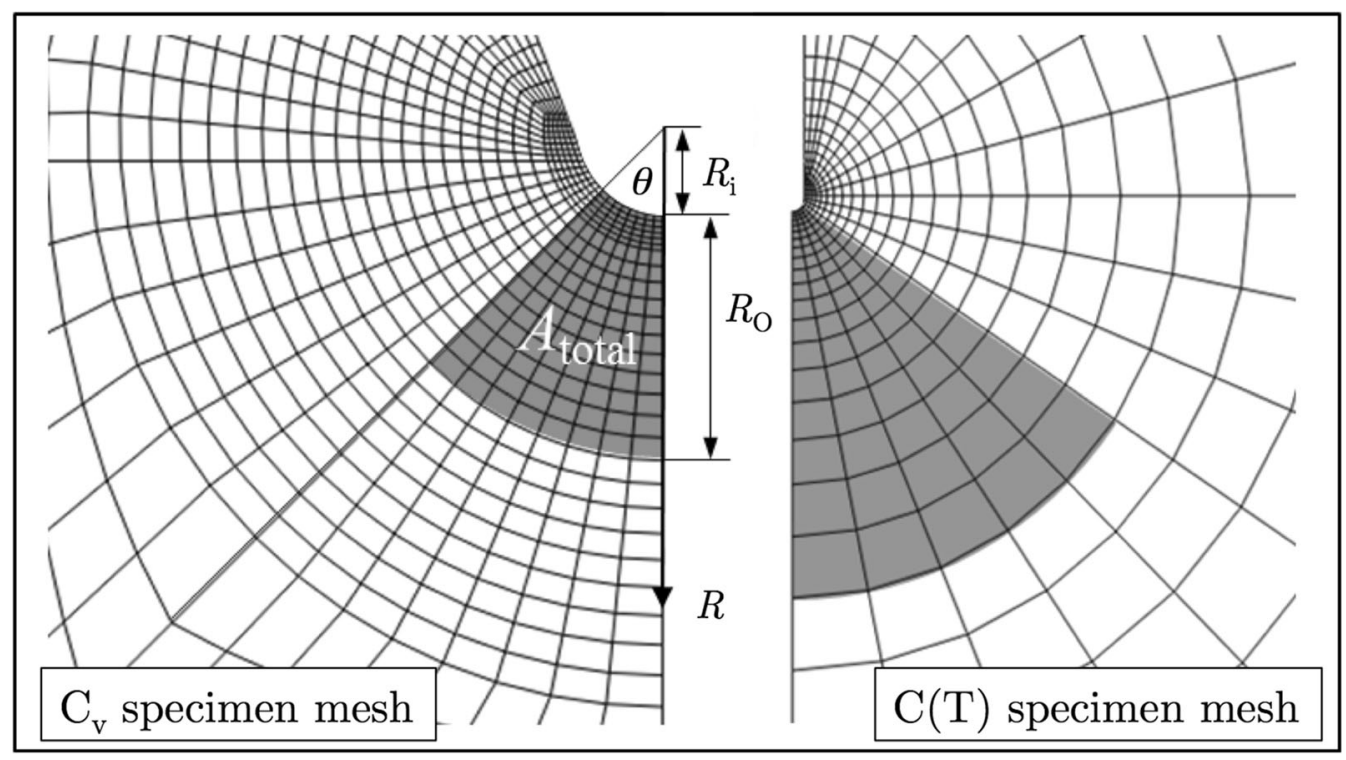

Fig. 13-Definition of crack tip weighted area used for analysis of RT parameter values for the CT specimen, not to scale.

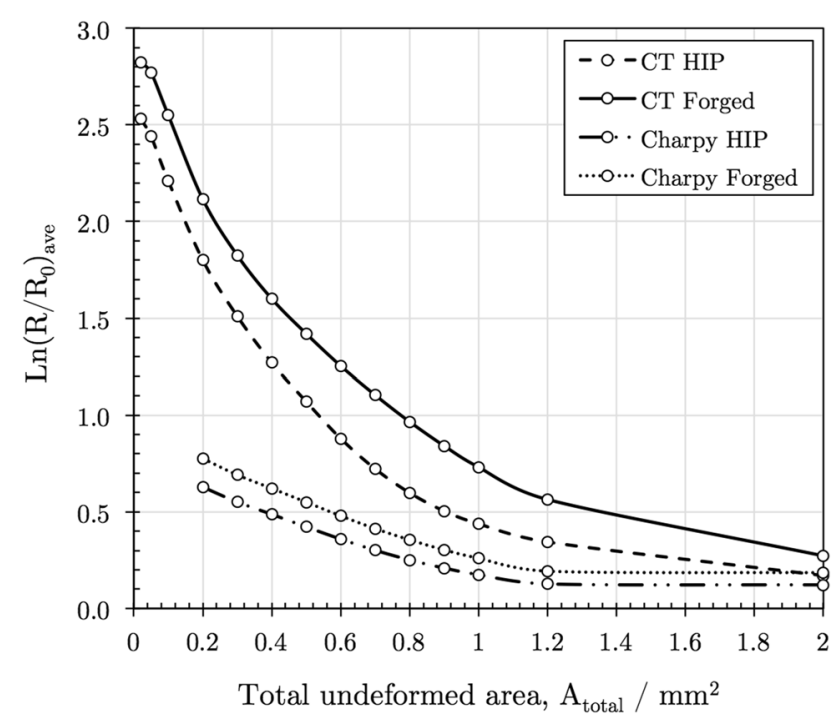

Fig. $14-\operatorname{Ln}\left(R / R_{0}\right)_{\text {ave }}$ values calculated over incremental areas from the crack/notch tip for Charpy and CT specimens at their respective fracture initiation toughness, as defined earlier.

between the two testing configurations, namely, the loading conditions, specimen size and geometry, triaxiality at the tip of the crack/notch, and strain rate. All of these conditions will play a role in the rate/extent of growth a void can undergo prior to fracture. For example, since $\ln \left(R / R_{0}\right)$ is a function of stress triaxiality and equivalent plastic strain, and given the differences in stress-state triaxiality between the crack tip (root radius $=$ $0.01 \mu \mathrm{m})$ in a $\mathrm{C}(\mathrm{T})$ specimen with $a_{0} / W=0.55$ and a notch root (root radius $=0.25 \mu \mathrm{m}$ ) in a Charpy specimen with $a_{0} / W=0.2$, this could account for the much larger $\ln \left(R / R_{0}\right)$ obtained from the $\mathrm{C}(\mathrm{T})$ models.

It appears that the differences in void growth characteristics determined from Charpy and C(T) models are not directly translatable, though both testing configurations exhibit greater achievable void growth in F304L than HIP304L. Interestingly, it can be seen that voids in the Charpy specimens (Figures 2(c) and (d)) are elongated in the direction of maximum plastic strain, in both HIP304L and F304L. The degree of elongation (growth) is clearly greater in F304L; however, since the RT damage parameter assumes spherical void growth, the results obtained from the Charpy models might be less accurate than those obtained from the $\mathrm{C}(\mathrm{T})$ models.

Finally, by calculating the average $\ln \left(R / R_{0}\right)$ over equivalent microstructural areas, it is thought that larger $\ln \left(R / R_{0}\right)$ values are obtained in the $\mathrm{C}(\mathrm{T})$ models as a result of (a) a denser, more localized plastic zone, which is more confined to the crack tip, and (b) nonspherical void growth in the Charpy specimen. Both of these phenomena are governed by the higher triaxial stress state at the tip of a crack when compared to a blunt notch. In addition, the quasi-static strain rates of the CT test are more favorable to void growth when compared to the Charpy models, since inertial effects are not present.

\section{CONCLUSIONS}

We have performed finite-element analyses on HIP'd and forged $304 \mathrm{~L}$ stainless steel for both $\mathrm{C}(\mathrm{T})$ fracture mechanics models and Charpy impact models, in order to characterize a material's fracture initiation behavior in terms of ductile void growth, through use of a void growth damage model as proposed by Rice and Tracey. We have performed experimental testing in order to (a) to validate the numerical models, and (b) provide

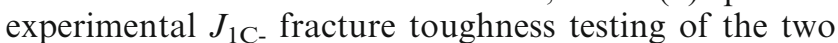
materials. By combining the experimental data and numerical analyses, we have acquired fracture "initiation energy" approximations for the two types of stainless steel under two different loading conditions.

In the numerical simulations we have calculated $\ln (R /$ $\left.R_{0}\right)$ for both materials and test specimens, and we have 

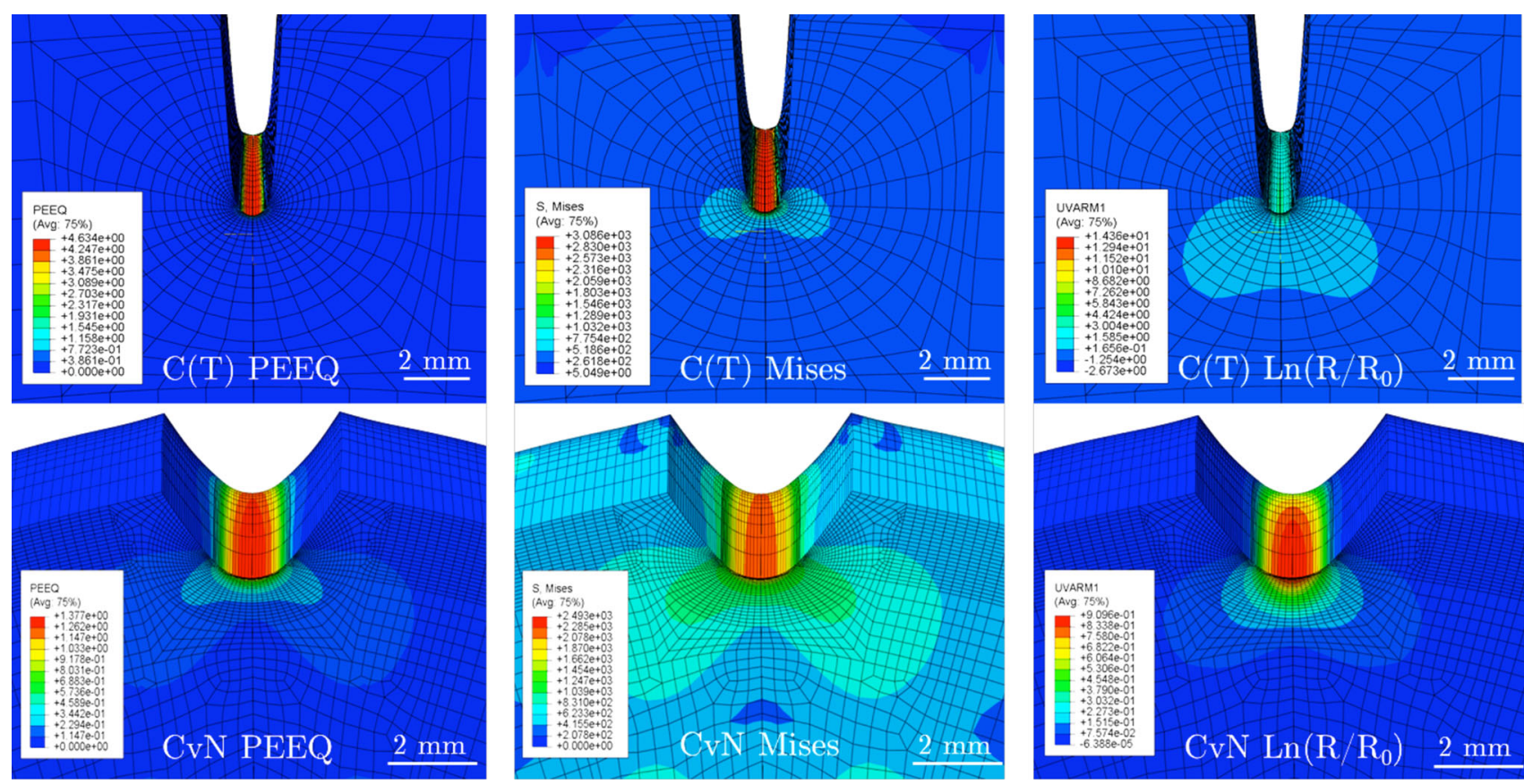

Fig. 15 - Contour maps showing the development of PEEQ, von Mises stress, and $\ln \left(R / R_{0}\right)$ with distance ahead of the tip of the V-notch in the F304L Charpy specimen and the- crack tip in the F304L C(T) specimen at their respective initiation increments.

studied how this damage criterion varies as a function of (a) loading history at the crack tip/notch root, and (b) distance directly ahead of the crack tip/notch root at the point of crack initiation, a value which we determined experimentally. We have shown that, in general, HIP304L and F304L exhibit similar void growth rate characteristics. However, when considering a material's critical $\ln \left(R / R_{0}\right)_{\mathrm{c}}, \mathrm{F} 304 \mathrm{~L}$ exhibits a larger $\ln \left(R / R_{0}\right)_{\mathrm{c}}$ than HIP304L and indicates that void growth in HIP'd 304L occurs over smaller distances than forged 304L before reaching a critical void growth and resulting in microvoid coalescence.

Finally, we have performed a comparison study between the materials and test specimens by calculating $\ln \left(R / R_{0}\right)_{\text {ave }}$ over equivalent microstructural areas (or length) in HIP304L and F304L and found that the average void growth is noticeably smaller ahead of the notch root in the Charpy specimens than ahead of the crack tip in $\mathrm{C}(\mathrm{T})$ specimens, which we believe is a result of several differences in testing arrangements, namely, the size of the plastic zone (governed by the triaxial stress-state conditions ahead of the crack/notch), strain rate of the tests, and nonspherical void growth observed in the Charpy specimens. In conclusions, we show that HIP304L and F304L stainless steel can be characterized in terms of void growth behavior, and can help to explain their differences in mechanistic fracture behavior.

\section{ACKNOWLEDGMENTS}

The authors thank the UK EPSRC for funding this research project. We are also grateful to Jean Dhers for advice and guidance and AREVA for the provision of materials. We are thankful to Messrs. Adam Bannister and Stuart Sotheran, Tata Steel, for measurement of the Charpy data. We also appreciate the efforts of Messrs. Vince McKee and Colin Burnfield, BAE Systems, for chemical analysis, and finally Amec Foster Wheeler for the use of their mechanical test equipment.

\section{OPEN ACCESS}

This article is distributed under the terms of the Creative Commons Attribution 4.0 International License (http://creativecommons.org/licenses/by/4.0/), which permits unrestricted use, distribution, and reproduction in any medium, provided you give appropriate credit to the original author(s) and the source, provide a link to the Creative Commons license, and indicate if changes were made.

\section{REFERENCES}

1. H.V. Atkinson and S. Davies: Metall. Mater. Trans. A, 2000, vol. 31A, pp. 2981-3000.

2. G.A. Rao and M. Kumar: Mater. Sci. Technol., 1997, vol. 13, pp. 1027-31.

3. C. Barre: Adv. Mater. Processes, 1999, vol. 155, pp. 47-48.

4. A.S. Helle, K.E. Easterling, and M.F. Ashby: Acta Metall., 1985, vol. 33, pp. 2163-74.

5. Y.C. Jeon and K.T. Kim: Int. J. Mech. Sci., 1999, vol. 41, pp. 815-30.

6. H.T. Larker and R. Lundberg: J. Eur. Ceram. Soc., 1999, vol. 19, pp. 2367-73.

7. G. Byrne, M.A. Spence, B. Olsen, P.J. Houghton, and J. McMahon: TWI Paper 19, 1994. 
8. A.J. Cooper, N.I. Cooper, A. Bell, J. Dhers, and A.H. Sherry: Metall. Mater. Trans. A, 2015, vol. 46A, pp. 5126-38.

9. A.J. Cooper, N.I. Cooper, J. Dhers, and A.H. Sherry: Metall. Mater. Trans. A, 2016, vol. 47A, pp. 4467-75.

10. A.J. Cooper, J. Dhers, and A.H. Sherry: 2016, p. V06AT06A012.

11. P.F. Thomason: Ductile Fracture of Metals, Pergamon Press, Oxford, United Kingdom, 1990.

12. D. François, A. Pineau, and A. Zaoui: Mechanical Behaviour of Materials: Volume II: Fracture Mechanics and Damage, Springer Science \& Business Media, Berlin, 2012.

13. R. Kiran and K. Khandelwal: Eng. Fract. Mech., 2013, vol. 102, pp. 101-17.

14. R.W. Bauer and H.G.F. Wilsdorf: Scripta Metall., 1973, vol. 7, pp. 1213-20.

15. A.A. Benzerga, J. Besson, and A. Pineau: J. Eng. Mater. Technol., 1999, vol. 121, pp. 221-29.

16. J.R. Rice and D.M. Tracey: J. Mech. Phys. Solids, 1969, vol. 17, pp. 201-17.

17. F.A. McClintock: J. Appl. Mech., 1968, vol. 35, pp. 363-71.

18. M.G. Cockcroft and D.J. Latham: J. Inst. Met., 1968, vol. 96, pp. 33-39.

19. A.L. Gurson: J. Eng. Mater. Technol., 1977, vol. 99, pp. 2-15.

20. G. Straffelini and V. Fontanari: Eng. Fract. Mech., 2011, vol. 78, pp. 1067-76.

21. ASTM E112-13: Standard Test Methods for Determining Average Grain Size, ASTM International, West Conshohocken, PA, 1996.

22. ASTM A370-14: Standard Test Methods and Definitions for Mechanical Testing of Steel Products, ASTM International, West Conshohocken, PA, 2014.
23. ASTM E8/E8M: Standard Test Methods for Tension Testing of Metallic Materials, ASTM International, West Conshohocken, PA, 2010.

24. ASTM E1820: Standard Test Method for Measurement of Fracture Toughness, ASTM International, West Conshohocken, PA, 2003.

25. ASTM E3-11: Standard Practice for Preparation of Metallographic Specimens, ASTM International, West Conshohocken, PA, 2001.

26. F.M. Beremin: IUTAM Symp. on Three-Dimensional Constitutive Relations and Ductile Fracture, North-Holland Publishing Company, Dourdan, France, 1981.

27. T.L. Anderson: Fracture Mechanics: Fundamentals and Applications, CRC Press, Boca Raton, FL, 2005.

28. P.S. Follansbee: J. Eng. Mater. Technol., Trans. ASME, 2012, vol. 134.

29. S.S. Hecker, M.G. Stout, K.P. Staudhammer, and J.L. Smith: Metall. Trans. A, 1982, vol. 13A, pp. 619-26.

30. W. Lee and C. Lin: Mater. Sci. Eng. A, 2001, vol. 308, pp. 124-35.

31. L.E. Murr, K.P. Staudhammer, and S.S. Hecker: Metall. Trans. A, 1982, vol. 13A, pp. 627-35.

32. S.F. Kane, A.L. Farland, T.A. Siewert, and C.N. McCowan: Weld. J., 1999, vol. 78 (8), pp. 292.s-300.s.

33. BS 7448-4: Fracture Mechanics Toughness Tests-Part 4, 1997.

34. R. Taktak, N. Benseddiq, and A. Imad: Fat. Fract. Eng. Mater. Struct., 2009, vol. 32, pp. 525-30.

35. Z. Wang: J. Appl. Phys., 1994, vol. 76, pp. 1535-42.

36. W. Tong and G. Ravichandran: J. Appl. Mech., 1995, vol. 62, pp. 633-39. 